Stereotactic

and Functional

Neurosurgery
Stereotact Funct Neurosurg 2015;93:190-193

DOI: $10.1159 / 000380825$
Received: August 28, 2014

Accepted after revision: February 10, 2015

Published online: April 1, 2015

\title{
Successful Use of High-Frequency Spinal Cord Stimulation Following Traditional Treatment Failure
}

\author{
Heather Smith Youngwon Youn Julie G. Pilitsis \\ Department of Neurosurgery, Albany Medical College, Albany, N.Y., USA
}

\section{Key Words}

Spinal cord stimulation, high-frequency $\cdot$ Chronic pain

\begin{abstract}
Introduction: High-frequency spinal cord stimulation (HFSCS) offers an alternative treatment for chronic refractory pain syndromes nonresponsive to traditional spinal cord stimulation (SCS). Following the conflicting findings of preliminary HFSCS clinical studies performed at $5-10 \mathrm{kHz}$, this study is the first to report successful clinical usage of $1-\mathrm{kHz}$ frequency SCS with a standard generator. Patients: We used HFSCS in 2 patients who had inadequate relief with traditional SCS. Patient 1 was initially programmed at $40 \mathrm{~Hz}$ and a pulse width of $330 \mu$ s with bipolar stimulation. After multiple setting adjustments with inadequate pain relief, the patient was reprogrammed to HFSCS at settings of $1.15 \mathrm{kHz}$, $120 \mu \mathrm{s}$, and $5 \mathrm{~V}$. Patient 2 was initially programmed at a frequency of $1.2 \mathrm{kHz}$ and a pulse width of $120 \mu \mathrm{s}$, which she favored over the standard setting of $40 \mathrm{~Hz}$ and $390 \mu$ s pulse width. HFSCS provided optimal pain alleviation and increased quality of life for both patients. Conclusions: HFSCS at the frequency of $1 \mathrm{kHz}$ offers a new tool for treatment of chronic pain in patients with traditional stimulation settings. Furthermore, most standard SCS batteries are capable of delivering stimulation in this frequency range.
\end{abstract}

(c) 2015 S. Karger AG, Basel (c) 2015 S. Karger AG, Base

$1011-6125 / 15 / 0933-0190 \$ 39.50 / 0$

\section{Introduction}

Spinal cord stimulation (SCS) is a widely accepted, FDA-approved treatment for management of chronic pain syndromes. Over 30,000 individuals receive SCS implantation on an annual basis for chronic pain, thus creating a growing industry in neuromodulation with annual sales exceeding USD 1.8 billion [1]. In comparison to pharmacological treatment alone, SCS patients report higher quality of life, greater pain relief, and more normal resumption of physical activity, including employment [1]. Nevertheless, despite the expanding use of this alternative therapy many patients who qualify as suitable candidates for SCS fail to attain pain relief.

Currently there is no general consensus regarding optimal stimulation parameters, which is reflected in the significant SCS failure rate at 30\% $[1,2]$. Although the electrically induced paresthesias are usually well tolerated a significant minority of patients find this sensation intolerable, which often leads to device removal [3]. Recent studies speculate this discomfort is attributable to nonoptimal stimulation settings $[1,2,4]$. Experimental manipulation of technical aspects of SCS, such as stimulation parameters, electrode shape and geometry, localization, etc., may need further investigation to be improved for nonresponders considering such parameters have a significant impact on pain relief, comfort and clinical outcomes [1].

\section{KARGER 125}

E-Mail karger@karger.com www.karger.com/sfn
Julie G. Pilitsis, MD, $\mathrm{PhD}$

AMC Neurosurgery Group 47 New Scotland Avenue, MC 10 Albany, NY 12208 (USA)

E-Mail jpilitsis@yahoo.com 
In an effort to spearhead this ambiguity regarding optimal stimulation parameters, Shechter et al. [5] examined the effects of varying stimulation frequencies and intensities using a standard rat model of chronic neuropathic pain. Following L5 spinal nerve ligation, epidural electrodes were implanted into the rats to deliver stimulation between $50 \mathrm{~Hz}$ and $10 \mathrm{kHz}$ at different intensities (20, 40 and $80 \%$ of motor threshold). While both conventional and high-frequency stimulation reduced mechanical hypersensitivity after nerve injury a frequency- and intensity-dependent relationship was found in relation to such inhibition. The authors reported a greater inhibition at high-amplitude ( $80 \%$ motor threshold), high-frequency $1-\mathrm{kHz}$ SCS in comparison to high-amplitude $50-\mathrm{Hz}$ SCS [5].

In response to these enticing results, clinical trials have demonstrated heterogeneous conclusions regarding the usage of high-frequency SCS (HFSCS) in patients. A large, multicenter European study prospectively demonstrated effective chronic pain relief in patients with complex, difficult-to-treat chronic back pain using the Senza HFSCS system, capable of stimulation frequencies up to $10 \mathrm{kHz}$ [6]. Furthermore, of the same cohort of patients, of the $90 \%$ of patients that attended the 24 -month followup appointment all reported sustained pain relief [7]. However, this study is limited by the bias of its open-label trial design. In contrast, a double-blind, placebo-controlled study found no significant difference in outcomes when comparing traditional SCS and $5-\mathrm{kHz}$ HFSCS [8].

This case report is the first to validate clinical efficacy of $1-\mathrm{kHz}$ frequency SCS with a standard generator. The capability of using $1-\mathrm{kHz}$ frequency stimulation may provide a new tool for treatment of chronic pain in patients who fail to find relief with traditional stimulation settings, not requiring the need for alternative device implantation.

\section{Case 1}

In October 2013, a 70-year-old female presented to our clinic for SCS treatment of complex regional pain syndrome following a car accident. The patient suffered chronic back pain for almost 20 years, which was refractory to all previous pain management methods including pharmacotherapy, physical therapy, epidural injections and radiofrequency lesioning. She initially presented on hydrocodone-acetaminophen and gabapentin $300 \mathrm{mg}$ t.i.d. The patient underwent a successful SCS trial, reporting a greater than $50 \%$ reduction in pain as well as improved sleep quality and overall quality of life. Paddle lead (model 39565-65 with RestoreSensor 37714, Medtronic, Minneapolis, Minn., USA) was placed via laminectomy with the top of the lead at the caudal aspect of T8. Stim-
Table 1. Patient 1: programming settings

\begin{tabular}{|c|c|c|}
\hline & HFSCS & Standard SCS \\
\hline Frequency, $\mathrm{Hz}$ & 1,150 & 40 \\
\hline Pulse width, $\mu$ s & 120 & 330 \\
\hline Electrode polarities & $(6+, 7-)$ & $(7+, 8+, 9-, 10-)$ \\
\hline \multicolumn{3}{|l|}{ Maximum tolerable } \\
\hline amplitude, $\mathrm{V}$ & 8.3 & 10.5 \\
\hline Comfortable amplitude, $\mathrm{V}$ & 5.0 & 3.5 \\
\hline Mode & $4 \mathrm{~s}$ on $/ 4 \mathrm{~s}$ off & $4 \mathrm{~s}$ on $/ 4 \mathrm{~s}$ off \\
\hline
\end{tabular}

ulation settings were programmed at $40 \mathrm{~Hz}$, pulse width of $330 \mu \mathrm{s}$ and an amplitude of $3.5 \mathrm{~V}$ (table 1).

Three months after surgery the patient was experiencing $80 \%$ pain relief in the morning and $60 \%$ pain relief in the evening, however, achievement of such relief required high amplitudes which caused unbearable paresthesias in her right leg. These paresthesias caused her to only use the device intermittently. We attempted several reprogramming sessions at which time we programmed the device varying frequency from 40 to $60 \mathrm{~Hz}$ and pulse width from 330 to $450 \mu$ s and attempting different electrode pairings. At the 6-month follow-up appointment the patient reported pain relief only $50 \%$ of the time, while the other half of the time the discomfort was severe.

We next attempted paresthesia-free stimulation with high-frequency stimulation at settings of $(6+, 7-), 1.15 \mathrm{kHz}$, pulse width of $120 \mu$ s, amplitude of $5.0 \mathrm{~V}$ (table 1). The patient reported better pain relief for the lower back with reduced leg paresthesia (numeric rating scale decrease from 6 to 3 ), and stated she would constantly use the HFSCS setting if she did not have the recharge burden every other day. She successfully uses the HFSCS program for relief at work and remains only on gabapentin $300 \mathrm{mg}$ daily at 6-month follow-up.

\section{Case 2}

In November 2013, a 56-year-old female presented to our department with intractable back and lower extremity pain, interested in pursuing SCS. The patient reported experiencing chronic pain affecting both of her hips, knees and ankles for over 10 years in part secondary to rheumatoid arthritis. The presenting pain level was 7 out of 10 in all affected areas, which caused joint pain and difficulty walking. Pharmacotherapy, physical therapy and epidural injections failed to alleviate ongoing symptoms.

After failing medical therapy, the patient completed a successful SCS trial. Interestingly, the standard settings resulted in no significant relief $(40 \mathrm{~Hz}, 390 \mu \mathrm{s}, 5.0 \mathrm{~V})$, so high-frequency stimulation settings were programmed at $1.2 \mathrm{kHz}$, a pulse width of $120 \mu$ s and an amplitude of $4.5 \mathrm{~V}$ (table 2 ). This resulted with a dramatic improvement in pain and greatly increased mobility. Two permanent $1 \times 8$ percutaneous leads were ultimately placed with their tips at the T7-8 interspace (model 9778160 with RestoreSensor SureScan 97714, Medtronic).

While the patient was essentially pain-free with HFSCS, she had $80 \%$ pain relief from standard SCS, which allowed her enough 
Table 2. Patient 2: programming settings at time of trial

\begin{tabular}{|c|c|c|}
\hline & HFSCS & Standard SCS \\
\hline Frequency, $\mathrm{Hz}$ & 1,200 & 40 \\
\hline Pulse width, $\mu$ s & 120 & 390 \\
\hline Electrode polarities & $(11-, 12+, 13+)$ & $(6-, 7+)$ \\
\hline \multicolumn{3}{|l|}{ Maximum tolerable } \\
\hline amplitude, $\mathrm{V}$ & 8.0 & 10.5 \\
\hline Comfortable amplitude, $\mathrm{V}$ & 4.5 & 5.0 \\
\hline Mode & $4 \mathrm{~s}$ on $/ 4 \mathrm{~s}$ off & $4 \mathrm{~s}$ on $/ 4 \mathrm{~s}$ off \\
\hline
\end{tabular}

benefit for quality of life without the daily recharge burden. At 1 year, she reported being able to complete challenging physical activities, such as hiking. Her numeric rating scale score decreased from 7 preoperatively to 0 at 1 year.

\section{Discussion}

HFSCS presents as a promising treatment option for chronic refractory pain syndromes. This report describes the successful usage of HFSCS in 2 patients who found no satisfactory outcome to conventional medical pain management, physical therapy, minimally invasive pain treatments, and inadequate relief with traditional SCS program settings. Despite the proven benefits of standard SCS, up to $30 \%$ of patients fail to experience relief $[1,2]$; thus, these cases convey exciting clinical implications.

For this treatment electrodes are surgically placed in the epidural space of the spinal canal, which allows for electrical stimulation of the dorsal columns of the spinal cord [9]. Predominately founded on Melzack and Wall's gate control theory, traditional SCS modulates pain via the stimulation of $A \beta$ fibers, therefore reducing nociceptive transmission from the periphery to pain-receptive areas of the brain [9].

Traditionally, SCS induces paresthesias in the patient's painful areas of the body, which relieves painful sensations; however, a significant minority of patients find the paresthesias intolerable, leading to device removal. There is mounting speculation that this failure can be prevented by optimizing stimulation settings $[1,2,4]$. In a recent review regarding the appropriate usage of SCS by the Neuromodulation Appropriateness Consensus Committee, it was suggested that HFSCS offers a solution to uncomfortable paresthesias, allowing for more comfortable pain relief with coverage of difficult mixed-type axial pain. Furthermore, lack of paresthesias allows for betterdesigned clinical trials with masked treatment groups to further the evidence base behind SCS usage [10]. Simi-
Table 3. Range of programming parameters in current FDAapproved devices

\begin{tabular}{|c|c|c|c|}
\hline & Medtronic & Boston Scientific & St. Jude \\
\hline Frequency, $\mathrm{Hz}$ & $2-1,200$ & $2-1,200$ & $2-1,200$ \\
\hline Pulse width, $\mu$ s & $60-1,000$ & $20-1,000$ & $50-500$ \\
\hline Amplitude & $0-10.5 \mathrm{~V}$ & $0-25.5 \mathrm{~mA}$ & $0-25.5 \mathrm{~mA}$ \\
\hline \multirow{3}{*}{$\begin{array}{l}\text { Implanted pulse } \\
\text { generator } \\
\text { model }\end{array}$} & model 97714 & Precision & Protégé IPG ${ }^{\circledR}$ \\
\hline & RestoreSensor $^{\circledR}$ & Spectra $^{\mathrm{TM}}$ & \\
\hline & SureScan ${ }^{\circledR}$ MRI & & \\
\hline
\end{tabular}

larly, in a recent assessment on the future applications of SCS the author suggests that HFSCS will have better success in treating axial pain - low back pain, interscapular, upper back pain, neck pain - allowing for broader patient selection with the absence of paresthesias [11]. The potential application of this new stimulation paradigm remains extremely promising.

A study examining the efficacy of HFSCS in a standard rat model of neuropathic pain reported high-intensity, kilohertz-level SCS to provide earlier and more dramatic alleviation of mechanical hypersensitivity [5]. The authors further suggested the underlying mechanism of HFSCS differed from the traditional mechanism of SCS based on gate control theory. Using neuronal recording, the study documented reduced large $A \alpha-$ and $A \beta$-fiber activity, but not small C-fiber activity, thus questioning established models of SCS mechanisms [5].

Translation of these profound results into clinical practice has complicated these seemingly transparent findings. A large multicenter prospective study of HFSCS implemented in Europe revealed significant and 24month sustained relief of pain in a cohort of patients with difficult-to-treat lower back and leg pain (79\%) - notably, without uncomfortable paresthesia [6,7]. These results suggest an important usage of HFSCS in patients that fail to find relief with standard SCS, however, the findings are limited by the biased open-label trial design. In contrast, the findings of the double-blind, placebo-controlled study performed by Perruchoud et al. [8] contradict these results. No difference was found when comparing $5-\mathrm{kHz}$ HFSCS to the sham condition of standard SCS.

Following the discrepant findings of these preliminary HFSCS clinical studies, this study is the first to report successful clinical usage of $1-\mathrm{kHz}$ frequency SCS with parameters available with a standard generator (table 3 ). This case report remains in agreement with the results of Van Buyten et al. [6] and Al-Kaisy et al. [7], however, it suggests an important application of bailout usage of 
SCS. It is unclear if other, larger generators than the ones used in these cases may have less of a recharge burden. It is also possible that advanced programming settings may allow automated shuffling between HFSCS and standard SCS. Different frequencies of stimulation may have distinct benefits for particular cohorts of patients, and reoperation with placement of a special generator would not be necessary. Optimization of stimulation parameters allows for pain alleviation without intolerable paresthesias, a concept which may reduce the failure rate of such an advantageous treatment for chronic pain.

\section{Acknowledgments}

We would like to thank Renee Linton, BA from Medtronic for working with our patients to document their setting changes.

\section{Disclosure Statement}

Dr. Julie G. Pilitsis is a consultant for Medtronic, St. Jude and Boston Scientific and receives grant support from Medtronic, Boston Scientific, St. Jude and NIH 1R01CA166379. There was no support for this article from any company/institution.

\section{References}

1 Zhang T, Janik J, Grill W: Mechanisms and models of spinal cord stimulation for the treatment of neuropathic pain. Brain Res 2014; 1569:19-31.

$\checkmark 2$ Smits H, van Kleef M, Holsheimer J, Joosten EA: Experimental spinal cord stimulation and neuropathic pain: mechanism of action, technical aspects, and effectiveness. Pain Pract 2013;13:154-168.

3 Clark J: Spinal cord stimulation: does frequency matter? Anesthesiology 2013;119:243-244.

4 Molnar G, Barolat G: Principles of cord activation during spinal cord stimulation. Neuromodulation 2014;17(suppl 1):12-21.

5 Shechter R, Yang F, Xu Q, Cheong YK, He SQ, Sdrulla A, Guan Y: Conventional and kilohertz-frequency spinal cord stimulation produces intensity- and frequency-dependent inhibition of mechanical hypersensitivity in a rat model of neuropathic pain. Anesthesiology 2013;119:422-432.
Van Buyten J, Al-Kaisy A, Smet I, Palmisani S, Smith T: High-frequency spinal cord stimulation for the treatment of chronic back pain patients: results of a prospective multicenter European clinical study. Neuromodulation 2013;16:59-66.

7 Al-Kaisy A, Van Buyten J, Smet I, Palmissani $\mathrm{S}$, Pang D, Smith T: Sustained effectiveness of $10 \mathrm{kHz}$ high-frequency spinal cord stimulation for patients with chronic, low back pain: 24-month results of a prospective multicenter study. Pain Med 2014;15:347-354. $\checkmark 8$ Perruchoud C, Eldabe S, Batterham A Madzinga G, Brookes M, Bovet N, Buchser E: Analgesic efficacy of high-frequency spinal cord stimulation: a randomized doubleblind placebo-controlled study. Neuromodulation 2013;16:363-369.

$\longrightarrow 9$ Stojanovic MP, Abdi S: Spinal cord stimulation. Pain Physician 2002;5:156-166.

$>10$ Deer TR, Mekhail N, Provenzano D, Pope J, Krames E, Leong M, North R: The appropriate use of neurostimulation of the spinal cord and peripheral nervous system for the treatment of chronic pain and ischemic diseases: the Neuromodulation Appropriateness Consensus Committee. Neuromodulation 2014; 17:515-550.

11 Slavin K: Spinal stimulation for pain: future applications. Neurotherapeutics 2014;11: 535-542. 